\title{
AS CONTRIBUIÇÕES AOS ASPECTOS COGNITIVOS EM DIFERENTES ABORDAGENS TEÓRICAS
}

\author{
Lídia Silveira Arantes ${ }^{1}$ \\ Talita Jéssica do Nascimento de Araújo ${ }^{2}$ \\ Júlio Eduardo Rohenkohl ${ }^{3}$ \\ Thales de Oliveira Costa Viegas ${ }^{4}$
}

\begin{abstract}
RESUMO
A noção de indivíduo, tal como seus aspectos ligados à cognição e aprendizagem, se diferencia na medida em que se altera a perspectiva teórica adotada para analisar esse tema. Nesse contexto, o presente trabalho pretende abordar diferentes prismas acerca da cognição dos indivíduos, os quais estão associados a abordagens teóricas distintas. Desta forma, o objetivo geral é o de resgatar abordagens teóricas que inserem a noção de indivíduo que altera, paulatinamente, sua forma de agir e decidir, mediante o aprendizado institucionalizado. Além disso, confronta a concepção de indivíduo com perfil de decisão único e repetido. Essa última concepção do indivíduo é apriorística e objetiva adequar o indivíduo ao marco epistemológico da precisão científica. Neste sentido, para uma construção mais afeita a processos de mudança são aportadas contribuições de três diferentes abordagens, com a indicação do grau de ruptura "incremental", representada pela proposição de utilidade de Lancaster e pela abordagem evolucionária neoschumpeteriana de Nelson e Winter, e a "radical", identificada com o institucionalismo original de Veblen. Enveredando pela troca interdisciplinar subjacente aos trabalhos de Veblen, aportamse contribuições de Richard Scott, e a noção de identidades de James March para uma melhor caracterização de sujeito cognoscente institucionalizado. Constata-se que a concepção radical é complementar à incremental evolucionária neoschumpeteriana na medida em que processos de aprendizagem tecnológico em organizações convergem para propensões a agir baseadas em identidades.
\end{abstract}

Palavras - chave: cognição, indivíduos, institucionalismo

\begin{abstract}
The notion of the individual, as well as its aspects related to cognition and learning, differs when it changes the theoretical perspective adopted to analyze this issue. In this context, this paper intends to address different prisms about the cognition of individuals, which are associated to different theoretical approaches. Thus, the general objective is to review theoretical approaches that insert the notion of individual that gradually changes the way they act and decide, through institutionalized learning. Moreover, it confronts the conception of the individual with a single and repeated decision profile. This last conception of the individual is aprioristic and aims adapting the individual to the epistemological framework of scientific precision. In this sense, contributions of three different approaches are provided for a more shuffling construction of change processes. The indication of the "incremental" degree of rupture is represented by Lancaster's utility proposition and the neoschumpeterian evolutionary approach of Nelson and Winter. The radical rupture identified with the original institutionalism of Veblen. Based on the exchange between interdisciplinary contents, associated with Veblen's works, Richard Scott's
\end{abstract}

\footnotetext{
${ }^{1}$ Mestranda pelo Programa de Pós-Graduação em Economia e Desenvolvimento (PPGE\&D), UFSM. E-mail: lidiaarantes@gmail.com

${ }^{2}$ Mestranda pelo Programa de Pós-Graduação em Economia e Desenvolvimento (PPGE\& D), UFSM. E-mail: araujotalita@hotmail.com

${ }^{3}$ Professor Adjunto do Departamento de Economia, UFSM, julioroh@gmail.com

${ }^{4}$ Professor Adjunto do Departamento de Economia, UFSM, thales.viegas@gmail.com
} 
contributions are used, as well the James March's notion of identities for a better characterization of the cognitively institutionalized subject. It is noted that the radical conception is complementary to the neoschumpeterian evolutionary approach incremental, to the extent that technological learning processes in organizations converge towards propensities to act based on identities.

Keyword: cognition, individuals, institutionalism

Área Temática 5.5: Mudanças técnicas, organizações e instituições.

JEL: B52: Institucional; Evolucionária.

\section{INTRODUÇÃO}

Conceitualmente, a "ciência cognitiva" é "o estudo da inteligência (aprendizagem, raciocínio, percepção, linguagem, memória, controle de movimento) que abrange várias disciplinas acadêmicas" (PINKER, 1954, p.8). Cabe ressaltar, contudo, que não há uma definição única quanto ao termo ${ }^{3}$, mas a concepção supracitada se aproxima da perspectiva que será abordada neste artigo. Adicionalmente, pretende-se explicitar das teorias abordadas, as que propuseram mudanças incrementais, a inflexão na utilidade de Lancaster e teoria evolucionária neoschumpeteriana, e a que rompeu com o conteúdo da concepção do indivíduo nos termos postulados pela economia tradicional, o institucionalismo vebleniano. Para repercutir e aprofundar as perspectivas do institucionalismo original vebleniano, aportam-se contribuições do sociólogo Richard Scott, e a noção de identidades do cientista político James March.

Nessa perspectiva, pretende-se destacar estudos que buscam compreender os indivíduos, os seus aspectos cognitivos e seus comportamentos, reforçando, assim, as críticas às concepções que classificam o indivíduo como plenamente "otimizador" nas suas tomadas de decisões. Ao ter como objeto de estudo o indivíduo, elementos como a cognição (processos da mente humana) se tornam centrais (ZULIAN, 2015). Nesta lógica, estruturas sociais com aspectos dinâmicos e passíveis de transformação são explicitadas. Esse dinamismo ocorre em decorrência de estímulos dos próprios indivíduos, bem como de pressões externas a eles em uma determinada realidade socioeconômica.

Considera-se, inicialmente, a instituição tal como cunhada pela teoria vebleniana, assim como o seu enfoque em aspectos cognitivos, que embasam o comportamento humano. Neste caso, as instituições representam, de forma resumida, os hábitos de pensamento que são socialmente compartilhados. Ademais, pretende-se realçar as limitações do paradigma econômico neoclássico, fundamentado na racionalidade individual, por ser incapaz de contribuir para a compreensão de uma realidade socioeconômica que evolui, ou seja, altera-se qualitativamente em aspectos como tecnologia, padrões de consumos, padrões de concorrência entre capitais.

Desse modo, almeja-se apresentar conceitos que conferem significativa importância ao tema, a saber: a ótica de racionalidade limitada, as representações mentais habituais, as estruturas cognitivas, que abarcam a afetividade e identidades. Para isso, teorias complementares mostram-se necessárias de serem incorporadas em estudos econômicos que visam estabelecer relações com assuntos de natureza psicológica, filosófica, sociológica ou antropológica, evidenciando o caráter multidisciplinar acerca do tema em questão.

O presente trabalho tem cunho teórico e objetiva apresentar uma discussão dos aspectos cognitivos presentes nos indivíduos à luz de diferentes teorias. Utilizou-se da pesquisa bibliográfica para discutir os aspectos teóricos fundamentais sob a ótica de distintos autores. Nessa tipologia de método de pesquisa algumas teorias são criticadas e outras apresentadas como opções mais realistas ou mais rigorosas do ponto de vista científico. Neste sentido, utiliza-se deste método para mostrar o dialógico crítico entre as teorias cotejadas (DEMO, 1985).

\footnotetext{
3 A cognição pode referir-se às coordenações de ações e relações interpessoais respaldadas no domínio do conhecimento (MATURAMA, 2001, p.105)
} 


\section{DA TEORIA TRADICIONAL AO APRENDIZADO DO INDIVÍDUO: O CARÁTER INCIPIENTE DA COGNIÇÃO.}

A racionalidade ilimitada dos agentes econômicos é um dos principais pressupostos presentes na abordagem tradicional ${ }^{4}$, na qual os agentes tomam decisões de forma maximizadora, a partir de cálculos precisos, e não incorrem em erros (NELSON \& WINTER, 2005). A abordagem tradicional, ou análise econômica, compreende teorias tais como a neoclássica, mercados contestáveis, teoria do agenteprincipal. O que liga todas elas é $i$ ) a partição do todo em unidades médias homogêneas cujas ações decisórias se direcionam para fins claros, ações estas que podem ser somadas; ii) a redução do comportamento de cada parte - a pessoa ou a organização com coordenação e autonomia de decisão, o indivíduo -, a um processo único de decisão racional; e iii) a epistemologia da precisão, ou seja, o entendimento que a ciência é definida por afirmações exatas e formalizadas. Nesta abordagem, estão presentes concepções irrealistas acerca da natureza humana, como bem destaca Conceição (2002). Em síncrono com tal percepção, Veblen (1919) argumenta que a descrição do indivíduo é incipiente, ao considerá-lo imutável, passivo e estático.

Diante da definição do indivíduo para teoria tradicional, cabe analisarmos o processo de tomada de decisão concebido como resultado de escolha racional, o qual ocorre em etapas sequenciais, descritas a seguir: i) aparecimento, no indivíduo, de uma necessidade ou desejo; ii) presença de atributos ou alternativas a serem escolhidas; iii) antecipação das consequências da decisão; iv) avaliação e comparação de alternativas (tendo como base que o indivíduo é capaz de fazer todos os cálculos de forma a captar todas as informações disponíveis). Desta forma, verifica-se a elaboração das funções utilidades, em consonância com as alternativas preferíveis e, por fim, é tomada a decisão com base na alternativa selecionada (LOUVIERE, HENSHER \& SWAIT, 2000; MARCH, 1994).

O processo de escolha depende de alguns pontos, quais sejam: as características individuais socioeconômicas dos agentes (idade, escolaridade, renda, dentre outros). Com isso constata-se que alguns atributos são determinantes para a tomada de decisão do agente e a escolha se desdobra na satisfação máxima das necessidades dos indivíduos (LOUVIERE, HENSHER \& SWAIT, 2000). Neste sentido, alguns estudos de corrente ortodoxa, sustentam que a motivação humana é guiada pelo desejo de maximização de utilidade (CERQUEIRA, 2008). A hierarquia da utilidade resulta das escolhas individuais, que são feitas mediante os atributos inerentes ao produto, ou seja, atribui-se ao consumo do bem determinado nível de utilidade (LANCASTER, 1966).

Com base nas noções expostas acima, podemos observar que na teoria tradicional, a escolha leva em consideração puramente o desejo de consumo do bem específico. Neste caso, apesar da abertura para que os consumidores tenham gostos (preferências) diferentes uns dos outros, a preferência é como que um estado psicológico ou cultural inexplicado pela teoria econômica, ou seja, uma variável externa. Ao externalizar os fundamentos das preferências, a economia também se abstém de investigar a mudança nas preferências. O recurso, então, é considerar as preferências dos indivíduos como dadas (definidas e imutáveis) durante o tempo (abstrato) de análise. Por não contemplar essas questões da especificidade dos bens e da origem das preferências, que envolvem a utilização de informações relevantes pelos consumidores, esta teoria é criticada por ser "vazia” (LANCASTER, 1966).

\subsection{Rupturas incrementais}

\subsubsection{As proposições de Lancaster}

Conforme discutido anteriormente, a teoria tradicional do consumidor apresenta lacunas no que diz respeito à definição da relação entre as preferências, associadas ao consumo de bens, uma vez que a existência de substituibilidade e complementariedade dos bens, em relação aos outros, é considerada uma propriedade intrínseca às preferências, que são base para tomada de decisão de consumo. A abordagem

\footnotetext{
${ }^{4}$ A teoria tradicional remete a teoria neoclássica em sentido amplo que nasceu em diversos países, sob culturas econômicas diferentes, quase ao mesmo tempo - ou seja, na década de 1870. Entre os pioneiros acham-se Hermann Heinrich Gossen, na Alemanha; Carl Menger, na Áustria; Léon Walras, na Suíça; Stanley Jevons e Alfred Marshall, na Inglaterra (PRADO 2001).
} 
diferenciada para teoria do consumidor é proposta, por Lancaster (1966), a partir de diferentes percepções acerca da dinâmica da utilidade e da tomada de decisão de consumo dos agentes. Diferentemente do tratamento dado à utilidade obtida, proporcionalmente, aos bens adquiridos, os consumidores conferem centralidade às "propriedades" ou características (diferentes) dos bens. Esse enfoque se apresenta como uma visão mais realista do comportamento do consumidor, em relação à abordagem tradicional, por assumir e conceber o consumo dentro de uma ótica de diferenciações essenciais e determinantes para escolha (LANCASTER, 1966). Por essa razão apresenta-se como uma ruptura incremental à noção de indivíduo definido pela teoria tradicional apresentado anteriormente.

A inovação teórica proposta por Lancaster está em derivar utilidade das diversas características de um bem em lugar de ligá-la diretamente do consumo do bem ou serviço em si. Um bem é concebida como um input para suprir a satisfação de um conjunto de características desejadas pelo consumidor. Um ordenamento de utilidade, então, está ligado diretamente a conjuntos de características e apenas indiretamente aos bens que as satisfazem. Exemplificando, um alimento como a soja orgânica possui um conjunto de características nutricionais, e também uma séria de propriedades estéticas e um grupo de aspectos sanitários. Outros alimentos contemplam estas características de maneira e em proporções distintas.

Diante das limitações da teoria tradicional, Luppe e Angelo (2006) afirmam que Lancaster (1966) propôs uma nova abordagem para a teoria do consumidor, que introduziu uma análise mais realista acerca das características dos bens no comportamento do consumidor. Estes autores apontam que o consumidor não obtém utilidade diretamente através da compra dos bens. A utilidade advém das propriedades ou características específicas e distintivas dos bens. Admite-se que, na prática do consumo, o indivíduo considera o conjunto de suas características idiossincráticas. E isso quer dizer que há considerações dos consumidores para aspectos diferentes dos bens, como a percepção relacionada à qualidade, que é considerada diferente quando os bens são comparados.

No trabalho desenvolvido por Lancaster (1996) sugere-se que a introdução das características dos bens são aspectos determinantes da demanda, pois diferentes características representam diferenciações nos produtos. Cabe ressaltar que a percepção dos consumidores quanto a essas características também influencia o ato de consumir e pode alterar-se mediante a posição social na qual eles pertencem.

Essa nova abordagem contém os seguintes pressupostos: i) o bem, por si só, não confere utilidade ao consumidor, pois o que gera utilidade são as suas características; ii) em geral, um bem possuirá mais de uma característica e muitas destas podem ser compartilhadas por mais de um bem e; iii) as combinações de mercadorias podem possuir características diferentes das que pertencem aos bens isoladamente, ou seja, quando os bens são combinados podem apresentar características diferentes de quando contemplados separadamente. Além disso, um dos aspectos mais importantes da teoria do comportamento do consumidor é a reação desse agente às variações de qualidade dos produtos (LANCASTER, 1966).

No entanto, mesmo com evoluções na teoria tradicional, a concepção de cognição, explicitada pela tomada de decisão de consumo, ainda é incipiente. Isso porque, propriedades intrínsecas, relacionadas ao consumo de bens, tais como status, crenças, valores, identidades, dentre outros, não são abordadas. Além disso, os fatores humanos abstrusos são dotados de demasiada complexidade.

\subsubsection{Evolucionários neoschumpeterianos}

Contribuições relevantes, que também dão ênfase às questões cognitivas, são encontradas nos trabalhos de autores neochumpeterianos, que consideram a mudança e as inovações como os seus aspectos centrais para a explicação da ciência evolucionária. Cabe ressaltar que eles acreditam que os indivíduos possuem racionalidade limitada, no sentido cunhado por Simon em 1950. A racionalidade limitada difere da racionalidade desenvolvida pelos neoclássicos e salienta que indivíduos estão suscetíveis a cometer erros e omissões, bem como a apresentar comportamento satisfatório em lugar do ótimo (STEINGRABER E FERNANDES, 2013). A economia evolucionária neoschumpeteriana indica que os sistemas econômicos são os cenários onde empresas concorrentes buscam diferenciais competitivos, em ambiente de mudanças e evolução, bem como são impulsionadas pela inovação 
contínua. Os seres humanos são fundamentais nesse processo, pois podem agir deliberadamente no processo de inovação, ao pensar em novas soluções, realizar pesquisas e apresentar novas ideias (NELSON, 2002).

$\mathrm{Na}$ perspectiva da racionalidade limitada, ainda persiste a visão do indivíduo que faz projeções acerca de suas ações, em relação às decisões a serem tomadas, sem "abrir mão" de relativa previsibilidade, no âmbito das consequências das suas escolhas. Nesta lógica, o que guia suas ações também são as avaliações das consequências, que podem ser permeadas por um número excessivo de ações admissíveis, sem poder ser computadas de forma precisa. Fica claro que o indivíduo, tal como cunhado por Simon, percebe e reflete acerca das suas possíveis ações, evidenciando que a racionalidade limitada não é irracionalidade (STEINGRABER E FERNANDES, 2013).

A teoria do comportamento racional preocupa-se em compreender as características dos agentes em ambientes de incerteza e complexidade. Os atributos cognitivos afloram mediante a tomada de decisões. Com isso, faz-se necessária a definição de racionalidade substantiva ou "otimizadora", desenvolvida pela corrente neoclássica, que assume que os resultados das ações humanas podem ser previstos precisamente e antecipados. Já na racionalidade limitada encontra-se uma perspectiva mais realista a respeito das limitações os indivíduos e das regras de escolha que refletem na tomada de decisão, pois se admite que é possível encontrar resultado satisfatório ao traçar um curso de ação como "norte". Além do mais, a aprendizagem dos indivíduos na organização pode advir de respostas de estímulos das situações, tanto externas quanto internas (SIMON, 1978). Neste caso, apesar de incorporada a incerteza a lógica de consequencia permanece.

As escolhas racionais são tratadas como consequentes porque a ação é escolhida, ou a decisão é tomada, a partir da antecipação de uma consequência pelo indivíduo. O indivíduo pauta-se por uma lógica das consequências. Num ambiente estável, simples e no qual as informações estão disponíveis, os economistas supõem que a racionalidade seja substantiva, ou seja, as alternativas de ação e as suas consequências são bem definidas e as preferências do decisor são estáveis; ele avalia todas as alternativas simultaneamente e escolhe aquela que lhe proporciona um retorno ótimo (MARCH, 1994).

No entanto, se as informações não estão plenamente disponíveis e o ambiente não é simples porque existem muitas alternativas possíveis, os indivíduos movidos por uma lógica consequente limitam a sua atenção a um número reduzido de alternativas e avaliam-nas sequencialmente, uma após a outra. Agem com racionalidade limitada, almejando retornos satisfatórios de alguns indicadores que igualem ou superem níveis mínimos compatíveis com suas preferências (MARCH, 1994).

Autores neoschumpeterianos convergiram suas teorias com as noções de racionalidade limitada e processual de Simon, principalmente no que diz respeito à evolução das firmas e à sua adaptação ao ambiente externo. As firmas também não são capazes de maximizar decisões mediante a análise de todas as alternativas, pois não conseguem captar todas as informações presentes em um cenário de decisão. Dado esse contexto, regras de decisão, relativamente simples e processuais, são utilizadas para guiar a ação e as regras e processos não conduzem a resultados "ótimos", mas podem levar a resultados satisfatórios, quando atendem às metas delineadas pelos propósitos pré-determinados pela firma (STEINGRABER E FERNANDES, 2013).

Com a atenção dos evolucionários voltada para a organização como um corpo coordenado, a noção do indivíduo e sua cognição não experimentam ruptura radical, mas passam por modificações incrementais significativas, que vão ao encontro das especificações e explicações relacionadas às teorias da firma, no sentido de incluir as heterogeneidades presentes entre os indivíduos (as organizações), as quais decorrem dos processos cumulativos de aprendizagem produtiva e das tentativas de imitação.

De acordo com Nelson e Winter (1982), os modelos de maximização de escolha não abordam a questão da racionalidade limitada. Além disso, esclarecem que somente de forma metafórica um modelo de informação ilimitada pode ser considerado um modelo de decisão. Desta forma, tal modelagem é inadequada por não explicar (ou predizer) como o indivíduo se comportará efetivamente.

Os modelos maximizadores não dão centralidade à premissa comportamental que influencia a ação humana e as suas interações. E, sobretudo, incorrem em erros ao pressupor a "maximização" como uma característica humana (NELSON, 2002). Em contraponto com a vertente explicitada, Nelson (2002), afirma que parcela considerável do comportamento humano é vista como induzida, de forma 
relativamente automática, pelo contexto. Hábitos, rotinas, costumes, desempenham um papel importante na teoria econômica evolutiva. Alguns desses podem envolver padrões de comportamentos sofisticados, que exigem esforços cognitivos consideráveis e tempo de aprendizado, mas uma vez aprendidos, tornamse significativamente automáticos.

Nelson (2002) afirma que os indivíduos, operando em diferentes contextos que requerem a resolução de problemas, exploram alternativas objetivas (implementando coisas novas) e na própria mente (explorando alternativas). Desta forma, é possível descobrir e inventar maneiras de enfrentar o desafio, de modo a explicitar, assim, a sua capacidade cognitiva. Com isso, mostra-se que a solução de desafios humanos e organizacionais, em grande parte, se processa em estreita interação com o problema, ou seja, é uma atribuição humana a possibilidade de se voltar para o contexto de ação particular e refletir de forma mais geral. Isso envolve a inclusão de crenças que orientam a solução de problemas. Os esforços para "inventar" são vistos a partir de aspectos de "cultura coletiva", que incluem desde "boas práticas comerciais" até visões ideológicas comuns (NELSON, 2002).

Esse processo de escolha influencia a formação de rotinas. Nelson e Winter (1982) deram atenção para esse processo formativo e mostraram que ele possui fontes individuais e organizacionais. No que se refere às individuais, constata-se um enfoque nas habilidades humanas que correspondem, em grande medida, à capacidade de agir de forma coordenada e sequencial para o alcance de determinado objetivo. Tais habilidades seguem caminhos já determinados e são influenciadas por passos anteriores (ou outros passos que se complementam), podendo ser programáveis. O conhecimento que embasa essas habilidades é tácito, visto que quem executa não está consciente de seus detalhes e pode ter dificuldade de realizá-los. Apesar de envolver escolhas, podem se manifestar, como visto, de forma automática (NELSON e WINTER, 1982).

Constata-se que aquilo que está "por trás" das rotinas são as habilidades dos indivíduos. De acordo com Nelson e Winter (1982), as habilidades permitem aos indivíduos cumprir as tarefas. O modus operandi de uma organização condiz com o seu conjunto de habilidades, o que permite que tenham características próprias dependendo, desta forma, das habilidades individuais.

As habilidades, já mencionadas, podem levar a escolhas deliberadas ou não. Isto ocorre pelo fato de que as escolhas entre as opções de comportamento não envolvem necessariamente deliberação. Apesar disso, todo comportamento sequencial coordenado, verificado no exercício da habilidade, é um comportamento escolhido, pois rejeita grande variedade de comportamentos alternativos disponíveis. Para ilustrar o exposto acima, cabe citar o seguinte exemplo: quando um motorista faz ajustes no volante para permanecer na pista ele "escolhe" não deixar o carro sair da estrada, da mesma forma que "escolhe", quando acelera, alcançar um carro localizado a sua frente (NELSON e WINTER, 1982).

Desta forma, podemos afirmar que a escolha desempenha um papel maior na seleção de grandes decisões de comportamento do que nas pequenas, pois aquelas exigem nível de reflexão mais elevado. Já as menores decisões são realizadas em um grau mais alto de automatismo. Cabe aqui retomar o exemplo do carro, em que a seleção de escolhas sobre a velocidade pode se nortear tanto pela sinalização (como resposta aos limites publicados), quanto pela relação de custo e benefício de desviar rotas para chegada ao seu destino. Também é possível ser uma resposta automática à densidade do tráfego, às condições climáticas de condução, entre outras influências (NELSON e WINTER, 1982). Pode-se citar outro exemplo, de um motorista que foi multado recentemente. Neste caso, devido à "punição" pode tentar manter a velocidade baixa ao dirigir, no entanto, pode falhar, por causa de repostas automáticas presentes na sua cognição, e praticar velocidades mais altas que sua intenção (NELSON e WINTER, 1982).

A linha de argumentação explicitada em Nelson e Winter (1982) e Nelson (2002) permite afirmar que, embora os evolucionários neoschumpeterianos não sejam uma corrente específica do arcabouço teórico institucionalista, incorporam as instituições em suas análises. Com a atenção voltada para a organização como um corpo coordenado, a noção do indivíduo e sua cognição não experimentam ruptura radical, mas passam por modificações incrementais significativas, que vão ao encontro das especificações e explicações relacionadas às teorias da firma, no sentido de incluir as heterogeneidades presentes no indivíduo e apresentar argumentos alternativos ao que foi delineado pela teoria tradicional. Essas heterogeneidades apontadas decorrem de um processo de aprendizagem pela prática produtiva e pela 
imitação. No entanto, não é discutido o aparato cognitivo em profundidade, nem os fundamentos da ação e da decisão.

A automatização de propensões a agir derivadas de cultura coletiva significa uma inflexão frente à lógica de consequências, a qual implica deliberações renovadas a cada oportunidade de ação. Embora a organização escolha a execução da rotina, não delibera novamente a respeito de suas consequências; ela apenas associa dados contextuais que desencadeiam a execução da rotina incorporada. A rotina é teleológica: uma crise de lucratividade da organização forçará a sua revisão mediante uma deliberação racional limitada e processual. A possibilidade de inércia institucional, que não permita a implementação da mudança deliberada e leve à manutenção de rotinas ligadas a novos fins, necessita de apoio de um arcabouço teórico que rompa mais radicalmente com a lógica de consequência.

Tendo em vista as especificidades ligadas à cognição, presentes nas teorias schumpeterianas, entende-se que os ambientes de mudança, nos quais os indivíduos estão inseridos, são permeados de diferenciações. Com isso, aspectos heterogêneos relacionados ao comportamento e à habilidade dos indivíduos estão conectados às explicações referentes as diferenciações no bojo das firmas (tal como rotinas diferentes), mas não se apresentam, em um primeiro momento, como novo paradigma da leitura do indivíduo.

Fica evidente que para uma ruptura mais completa do paradigma do indivíduo calculador a noção de racionalidade limitada é insuficiente, pois, como visto, esta ideia não abre mão da vinculação correlata ao cômputo da ação, relacionada, por seu turno, às consequências.

\section{CRITICA RADICAL DA ABORDAGEM TRADICIONAL À LUZ DO PENSAMENTO DE VEBLEN}

Thorstein Bunde Veblen, considerado um dos fundadores da Economia Institucional Original, relaciona o seu conceito de instituição à noção de modelos mentais compartilhados, com base em instintos e hábitos. Dito isso, antes de aprofundar na abordagem de instituições, tal como formulada por Veblen, faz-se necessário destacar a sua crítica à economia tradicional ortodoxa, que é pautada, principalmente, em aversões aos pressupostos tais como: o "homo economicus", a "concorrência perfeita" e o "equilíbrio". Desse modo, cabe destacar que a visão do indivíduo para Veblen representará um rompimento dessa visão.

Cabe ressaltar que o conceito de homem econômico, ou seja, "homo economicus" representa uma abstração. Essa abstração decorre dos procedimentos científicos do século XIX que realizavam a fragmentação do objeto de pesquisa, ou seja, a repartição da realidade para fins de investigação analítica. Os economistas assumiram que o estudo das ações econômicas do homem poderia ser feito abstraindo-se as outras dimensões culturais do comportamento humano: dimensões morais, éticas, religiosas, políticas, dentre outros, além das influências psicológicas. Concentraram seu interesse naquilo que eles identificaram como as duas funções elementares exercidas por todo e qualquer agente econômico: o consumo e a produção (DA COSTA, 2010).

De forma peculiar, a economia, fundada na tradição neoclássica, se utilizou da matemática para e modelar o comportamento dos indivíduos, sejam eles, consumidores, empresas e outros agentes. Essa "peculiaridade" pode ser entendida como reflexo da noção oriunda do positivismo lógico 5 , intrínseca ao modo de fazer ciência no início do século XX, principalmente através do circuito de Viena. Este, por sua vez, demandava formalizações matemáticas e encadeamentos lógicos mensuráveis, na construção da ciência, com a justificativa de eliminar as assertivas de cunho metafísico. Desta forma, os lógicopositivistas almejavam construir uma "ciência" com base em elementos empíricos, apanhados na experiência sensível e traduzidos como recurso para a análise lógica (CAVALCANTE, 2007).

\footnotetext{
${ }^{5} \mathrm{O}$ positivismo lógico pode ser compreendido como o estudo da lógica e desenvolveu-se devido a ascensão do positivismo. Foi desenvolvido por membros do Círculo de Viena e também pode ser definido como empirismo lógico. Neste sentido, o conhecimento humano deve ter base em fundamentos científicos e lógicos. Desta forma, os pressupostos somente são válidos se for passíveis de formalização e verificação empírica. Os principais atributos desta teoria filosófica é o critério verificável à partir de métodos matemáticos e a oposição à metafísica.
} 
No trabalho de Veblen (1898), intitulado “Why is Economics Not an Evolutionary Science?”, se verifica uma negação explicita do caráter estático e equilibrista da economia clássica e neoclássica, bem como da concepção que aponta os agentes humanos como hedonistas dotados de uma natureza humana passiva e substancialmente inerte, imutável. Em contraste, os processos presentes na economia, na visão do autor, são concebidos como uma formulação teórica em que o agente central das mudanças é o ser humano, embasado em seus conhecimentos, habilidades e hábitos de pensamento (HODGSON, 1992). O autor constata que é inadequado, para uma teoria da conduta humana, considerar apenas as características individuais, de maximização de utilidades, em que aspectos relacionados às preferências dos indivíduos são desconsiderados, mesmo que o propósito seja uma análise estática (MONASTÉRIO, 2005).

Tendo em vista esta "visão" dos seres humanos, como agentes da mudança cultural, pode-se destacar que, muitas vezes, eles são moldados pelas circunstâncias materiais, sociais e tecnológicas, por um processo de causação cumulativa. Apoiado nisso, Veblen elaborou sua ideia de instituições como hábitos socialmente compartilhados do pensamento humano (ENDERLE E GUERRERO, 2008). O autor, mediante a sua concepção de sujeito e instituição, de suas inter-relações e interconexões, promove uma ruptura com a forma tradicional de conceber o indivíduo, o que o permite concentrar a atenção nos processos de mudança social e econômica.

De acordo com Rutherford (1984 apud Cavalcante, 2005), Veblen não apenas sugeriu a ideia de um processo evolutivo, mas também desenvolveu uma teoria dos instintos. Com isto arriscou-se a discutir fundamentos das propensões de comportamento dos consumidores e dos produtores, internalizando campo de análise econômico elementos externalizados pelo grupo de Viena em prol de um fazer científico obcecado pela precisão de indicadores numéricos e pela pretensão de estabelecimento de relações unívocas de causa e efeito.

A relação entre os instintos e instituições merece destaque. Cavalcante (2014) aponta que o "poder" das instituições, em alguns momentos, pode ser mais forte do que os dos instintos, no sentido de moldá-los. No entanto, o tema é controverso, pois o instinto não é puramente inconsciente e passível de molde. A ação dos seres humanos, como seres sociais, parte de uma "comunidade" e se constitui num produto complexo. Quanto maior as variantes materiais e sociais a que os indivíduos estão expostos, maior a dificuldade de discriminar as suas ações. Os aspectos que motivam a ação são os fins ou os objetivos, que então permitem guiar o homem (dotado de inteligência) para determinado caminho. Além disso, é necessário esclarecer que existem atributos inconscientes que também influenciam nas ações e estão fora da racionalidade imediata (SILVA, 2010).

O processo de causalidade cumulativa, a sobreposição de instituições, faz com que meios possam tornar-se fins, o que adiciona complexidade às decisões e ações dos sujeitos. Quando as instituições vinculam-se a novos objetivos, elas legitimam a sua permanência nas propensões a pensar e agir, ficam difíceis de mudar. A cumulatividade institucional altera os objetivos sociais e individuais.

No tocante à definição dos hábitos de pensamento, no arcabouço institucional, estes implicam a forma de ser e de fazer as coisas e podem ser mantidos ou modificados ao longo do tempo pela ação das pessoas, que são mediadas pela avaliação social normativa e regulativa. Nesse sentido, esses hábitos ou pensamentos podem ser absorvidos e apresentarem aceitação compartilhada, se tornando, assim, normas que orientam a ação e a conduta das pessoas. Podem, ainda, representar a maneira de agir e compreender o mundo, bem como de influenciar no surgimento de padrões e normas de uma aceitação de ação, que pode ocorrer de forma generalizada (CAVALCANTE, 2014).

Em consonância com essa definição, o conceito de instituição diz respeito à evolução da vida social, a partir de um processo contínuo, embora lento e gradual, de mudança nos hábitos de pensamento dos sujeitos. Assim, retornamos à compreensão vebleniana de instituições como hábitos de pensamento socialmente compartilhados, que se constituiriam em "métodos habituais de dar continuação ao modo de vida da comunidade em contato com o ambiente material no qual ela vive", ou seja, seriam as formas de decidir dos sujeitos que vão modificando ao longo do tempo (CAVALCANTE, 2015).

Ainda sobre a obra desse autor, cumpre salientar o conteúdo psicológico presente nas suas contribuições, por levar em consideração as questões instintivas e habituais. Além do mais, o autor faz menção ao papel da observação e da cognição na construção de hábitos e sua influência no padrão de consumo dos indivíduos. Contrariando a lógica dominada pela decisão racional, com gostos e 
preferências baseadas em análises construídas em nível individual, Veblen dá ênfase aos aspectos cognitivos dos sujeitos, principalmente ao introduzir outra maneira de analisar a tomada de decisão dos consumidores na ciência econômica. Esta questão fica mais clara quando se discorre a respeito da teoria relacionada ao consumo conspícuo (ALMEIDA, 2014).

Com destaque para os aspectos cognitivos, faz-se necessário explicitar a conexão entre impulsos internos para consumir bens, tal como o papel dos hábitos e instituições na condição de aspectos norteadores da busca por satisfação dos indivíduos e a centralidade dos instintos no consumo conspícuo. Aqui nota-se uma questão central, a saber: de que forma os consumidores percebem e associam os hábitos às instituições e como isso determina, ou melhor, influencia o seu comportamento?

Como base para esta discussão se encontra a noção de aprendizagem vicária, presente no trabalho "A evolução da teoria social cognitiva" de Albert Bandura (2005). O autor faz uma crítica ao behaviorismo por condicionar a aprendizagem, quase que prioritariamente, ao ato de aprender com os efeitos das próprias ações, ou seja, pela associação necessária entre estímulos ambientais e suas respostas. Desta forma, nega-se que a aprendizagem possa advir da observação. Ao se contrapor a essa tese, o autor defende que a aprendizagem pode se manifestar por "imitação", bem como que esta pode ser governada por crenças sociais e expectativas de resultados, em vez de ocorrer por liberação de reforçamento. Nessas condições, a modelação social (interpretada como imitação), pode implicar abstrair as informações dos modelos sobre a estrutura e princípios subjacentes, que governam o comportamento, ao invés de promover o simples mimetismo de resposta a exemplos específicos (BANDURA, 2005).

Os elementos determinantes dos desempenhos proficientes (ligados ao aprendizado), em comparação aos desempenhos improfícuos ainda estão obscuros; por isso, precisam ser explorados. Com isso, a modelação ganha relevância e as representações cognitivas, baseadas em modelos sociais, se apresentam como guias para a produção de desempenhos considerados hábeis e se estabelecem como padrões na interação em sociedade (BANDURA, 2005).

Em sociedade, as pessoas podem aprender por via de observação, aprendizado este que pode se concretizar de forma vicária, através da visualização do comportamento dos outros e de suas consequências. Para o autor, é através da observação do desempenho de outros, que as pessoas interpretam e dão significado constituindo-se assim um padrão de comportamentos. Os padrões, traduzidos em modelos, passam a ser utilizados como representações simbólicas a fim de nortear o comportamento (BANDURA, 1986). Neste sentido, o pensamento de Bandura é fundamental para explicação do consumo conspícuo de Veblen. Por isso, a sua obra é ressaltada como referência para o entendimento do denominado reforço vicário. Esse acontece mediante observação constante de um padrão de comportamento determinando, como o consumo conspícuo, em que os observadores desses padrões tentam replicá-lo.

$\mathrm{Na}$ medida em que estão claros os princípios criadores e, em alguma medida, fomentadores de aprendizado, considerados por Bandura, torna-se possível a melhor compreensão do consumo conspícuo. Este é realizado por um observador ativo em um cenário onde há possibilidade de aprendizado e se manifesta a partir de impulsos, em que há associação de consumo de bens com comportamentos emulativos, os quais, por seu turno, exigem observações vicárias, para tanto, utilização da cognição.

Nesta lógica, há uma interação permanente entre pessoas e instituições. E essa conexão ocorre por processos vicários, reforçadores e simbólicos. O papel central das habilidades cognitivas na aprendizagem vicária e o seu reforço é a interpretação dos símbolos dos observadores para que definam quais os comportamentos são considerados desejáveis. Afinal, do ponto de vista da economia institucional, a tomada de decisão é uma questão de habituação de questões sociais (ALMEIDA, 2011).

Outrossim, a existência do consumidor conspícuo de Veblen como observador, de acordo com a aprendizagem vicária de Albert Bandura, permite abordar explicações psicológicas sobre o motivo que torna a classe ociosa a instituição central nesta abordagem. Cumpre notar que há duas interpretações psicológicas da importância da classe ociosa. Uma é baseada na cognição e outra no comportamento, as quais são complementares. É possível, então, desenvolver padrões, através da observação do desempenho dos outros, que podem ser interpretados como "melhores" formas de comportamento, inclusive de consumo. Estas, por seu turno, podem ser incorporadas somente a partir da cognição, que neste caso, adquire aspecto central na aprendizagem vicária (ALMEIDA, 2014). 
A aprendizagem vicariante (ou por observação) possibilita o ato de aprender por similaridade entre o modelo e o observador, em que pode haver semelhanças entre as atividades realizadas, compatibilidade de comportamento do modelo com o repertório do observador e consequências baseadas em reforços (JUNIOR \& SOUZA, 2006). Cabe ressaltar que comportamentos aceitos socialmente, de forma generalizada (e incorporados repetidamente), podem se tornar um hábito que se desdobra em instituições.

Já que as decisões possuem o hábito como elemento central e os hábitos são formados e influenciados por modos e meios socialmente constituídos, não há como compreender a lógica do consumo excluindo o entendimento da emulação das classes. Pelos motivos já apresentados, a classe ociosa representa o guia para o entendimento dos significados do comportamento dos consumidores, que de certa forma, são resistentes à mudança, pois são adotados para explicitar as conexões com "bons exemplos". Estes, por sua vez, são constituídos, adotados e reproduzidos pelos consumidores como modelos do que é satisfatório. Essa é a explicação da importância prestada à cognição no processo de entendimento dos desdobramentos do consumo, baseada na existência da classe ociosa, presente na teoria de Veblen (ALMEIDA, 2014).

Veblen cita o impacto das instituições sobre o comportamento dos indivíduos. E estas podem atuar de duas formas: i) impor normais sociais de forma a restringir a conduta e; ii) influenciar no desejo dos agentes, que para ter esses desejos atendidos, pode, imitar o consumo da classe ociosa (MONASTÉRIO, 2005).

Cabe destacar, enfim, que Veblen nega a sentença de que os indivíduos agem de forma puramente automática perante os estímulos, assim como nega que os estímulos devem ocorrer, necessariamente, para que uma resposta seja dada. Não existe sequência lógica nem dependência de estímulo. Além do que, não haverá comportamento social se não existir mediação e interpretação de significados pelos indivíduos. (ALMEIDA, 2014).

Com essas explanações, tem-se claro o rompimento radical da conceituação do indivíduo nos moldes tradicionais, a partir de uma reconceituação baseada em hábitos, instintos e instituição. Ademais como a teoria vebleniana é abrangente, pode-se realizar um recorte ressaltando o seu conteúdo sociológico, psicológico e relativo à complexidade do indivíduo. Essa leitura fragmentada pode ser realizada, a partir da ótica do consumo vicário e da ótica do consumidor conspícuo, manifesto, como visto, na obra do autor.

A ruptura de Veblen é bastante radical porque ela introduz claramente uma perspectiva interdisciplinar. O seu aprimoramento também podem vir de trocas com outros campos das ciências sociais.

\section{FUNDAMENTOS COMPORTAMENTAIS NAS CIÊNCIAS SOCIAIS}

\subsection{A teoria institucional e enfoque cognitivo na abordagem de Scott}

As argumentações em linha com os pensamentos de Veblen têm características que remetem às ciências sociais lato sensu, os quais guardam semelhanças com estudos antropológicos, sociológicos e de ciência política. Longe de ser uma fragilidade do campo econômico, abrem a possibilidade de fertilizações cruzadas estre as especialidades científicas.

Uma contribuição importante e organizadora dos estudos de instituições foi dada pelo americano William Richard Scott (sociólogo e professor emérito na Universidade de Stanford), especializado em teoria institucional e ciência da organização. Para Scott (2008), as instituições são compostas por elementos regulativos, normativos, culturais e cognitivos, as quais possuem atividades associadas, promovem a estabilidade e o significado da vida social. Transmitidos de uma geração para a outra, os roteiros das ações delimitam espaços de ação, constrangem, expandem ou proíbem certos atos.

Neste enfoque, o pilar regulador apresenta como as instituições podem sancionar (punir ou premiar) os comportamentos de forma clara e previsível. O pilar normativo refere-se a valores e normas: prescritivo e avaliativo. Valores são conceitos associados ao que é preferível ou desejável, e manifestamse com a construção de padrões, necessários para definir comportamentos, e assim, poder ser comparados 
uns com os outros. Normas especificam como as coisas devem ser feitas. Representam, por exemplo, nas empresas, a capacidade de influenciar os funcionários, baseando-se no comportamento que está em conformidade com a obrigação e as necessidades sociais compartilhadas, as quais determinam o que é adequado na organização (WICKS, 2001). Ressalta-se que o não cumprimento das regras leva a possibilidade de sanções, estabelecidas tacitamente, cuja magnitude e forma de aplicação não estão previamente estabelecidas. Por fim, o pilar cultural-cognitivo se refere às regras que constituem a natureza da realidade e as estruturas por meio das quais o sentido é constituído. No pilar culturalcognitivo, o que o indivíduo faz é, em grande parte, uma função da representação interna de seu ambiente.

A existência dos três pilares supramencionados, que são reforçados reciprocamente, constitui a base para a legitimação da noção de instituição como estrutura constituída por esses elementos. Neste sentido, do ponto de vista institucional, a legitimidade não é uma simples "commodity" a ser possuída ou trocada, mas uma condição, que reflete alinhamento cultural, suporte normativo, ou consonância com regras e leis (SCOTT, 2005).

Scott (2005) salienta que as instituições (em todos os pilares) são imbuídas de três suportes, tais como a cultura, as estruturas sociais e as rotinas. O primeiro diz respeito a estruturas de interpretações por padrões codificados de sentidos e sistema de regras que informam e forçam comportamentos em curso e podem inclusive alterá-los. O segundo é apoiado por expectativas padronizadas que possuem conexão com a rede de papéis sociais. No último, as rotinas podem ser estruturadas como atividades na forma de comportamentos por hábitos. A padronização se manifesta pelo conhecimento tácito dos atores envolvidos, lembrando que hábitos podem ser profundamente enraizados e ter base em conhecimentos e crenças.

O pilar cognitivo diz respeito ao conhecimento social, compartilhado por meio de esquemas e estereótipos (MARKUS \& ZAJONK, 1985). De forma geral, podem representar os modelos de comportamento com base em regras e significados subjetivos, que influenciam os pensamentos, os sentimentos e as ações padronizadas, concebidas como apropriadas (WICKS, 2001).

Em seus aspectos cognitivos, as instituições podem incorporar símbolos, palavras, regras e aspectos de cultura. Tais elementos culturais são capazes de orientar a compreensão da natureza da realidade e dos quadros mentais em que o significado é construído (SCOTT, 2001).

Quando o sujeito passa a agir de acordo com o "correto" instituído socialmente, incorpora formas de agir e de pensar a partir da cognição e, para tal, são atribuídas formas de explicar a ação, que podem romper em parte com a racionalidade, pois é possível que o ser humano seja movido pelos sentimentos de aceitação e pertencimento, de modo a poupar deliberações. Verifica-se que o indivíduo age de determinada forma, pois quer se "sentir" inserido na cultura como membro. A racionalização ex-post pode justificar uma ação normatização cujo mote foi um sentimento. No exemplo da moda (padrão de vestimenta local), pode-se ter o seguinte questionamento: o indivíduo se utiliza de tais roupas como forma de adaptação ao clima ou de aceitação do grupo em que vive? O segundo componente pode estar presente.

Considerando a esfera cognitiva, são relevantes a interpretação e a cognição compartilhada, que se desdobram na ideia de cultura, a qual é, por sua vez, a agregação de significações e interpretações de ações e gestos. Além disso, a percepção dos problemas, e as possíveis tentativas de solução, implicam dialogar com as instituições já criadas que, por sua vez, estão condicionadas a aprendizados e ciclos anteriores, ou seja, as instituições do passado podem forjar a apreensão do presente.

Essa lógica representa a noção de agência do individuo. É atribuído ao agente individual a capacidade de vivenciar a experiência social e a partir dela nortear suas formas de enfrentar a vida, sob as mais extremas formas de coerção. Isso acontece mesmo em ambiente de limitação quanto à informação, permeado de incerteza, no qual estão presentes outras restrições (físicas, normativas ou políticoeconômicas). Nesta lógica os agentes sociais são capazes de resolver problemas, aprender como intervir no fluxo de eventos sociais ao seu entorno e monitorar continuamente suas próprias ações (LONG e PLOEG, 1989).

O "roteiro de ações" é institucionalizado e pode ser transmitido de uma geração para outra, delimitando, constrangendo ou proibindo certas ações, que podem se alterar ao longo do tempo. É importante observar que as instituições estão sempre em processos de mudança, sejam elas sociais, 
políticas e/ou econômicas. Conceber a mudança e os aspectos cognitivos do sujeito, conforme explicitado é essencial para entender as instituições.

Aportes sobre instituições desenvolvidos e debatidos na sociologia têm muitas convergências com as teorizações de Veblen. Destacam-se a atenção à cognição individual imersa em um contexto social, a tensão interativa entre estrutura e agente e a perspectiva de cumulatividade institucional.

A partir da relação entre pilares percebe-se que as normas tácitas serão sempre interpretadas mediante um aparato cultural-cognitivo, e ambos podem estar mais ou menos alinhados, ou seja, há convergências e clivagens. Da mesma forma, regras explícitas (pilar regulativo) também estão sujeitas à interpretação (cultural-cognitiva) e estão mais ou menos legitimadas na normatização tácita. A perspectiva de Scott é muito fértil por estruturar as instituições em pilares complementares e abre um caminho de investigação para aprofundar a compreensão dos períodos de estabilidade institucional ou das crises de valores e de comportamentos. Em relação às abordagens evolucionária neo-schumpeteriana e vebleniana, a relação entre aprendizado e normatização e regulação, seja na firma ou no ambiente de consumo, tem nos pilares de Scott um instrumento analítico complementar.

\section{COGNIÇÃO, AFETIVIDADE E IDENTIDADE SOCIAIS}

Outras teorias afloraram para explicar cognição e levaram em conta comportamentos, sentimentos e identidade dos indivíduos. Nesta lógica, os papéis que os indivíduos assumem socialmente são normatizados e institucionalizados. Um melhor entendimento desse fenômeno é possível pela leitura de James March (cientista político e professor emérito da universidade Stanford), que desenvolveu sua perspectiva teórica combinando psicologia e outras ciências sociais. Nesta teoria, rompe-se com a lógica baseada na necessidade de prever, mesmo que de forma imperfeita as consequências das ações. Aqui é inserida a noção de comportamento norteado pela busca do que é socialmente apropriado.

É relevante retomar os conceitos da teoria econômica tradicional que preveem que as decisões são tomadas de acordo com padrões de hierarquia, referente às utilidades. No entanto, essa teoria é inconsistente no que se relacionada à tomada de decisão por parte dos indivíduos, pois verificou-se aderência das escolhas dos indivíduos, às questões sociais. Isso pode ser evidenciado na prática do consumo, conforme afirmado por Garcia (2002). O consumo é delineado a partir de influência de grupos de referência. Por exemplo, o papel social que desempenha na família da qual faz parte impacta o seu padrão de consumo. Os fatores sociais devem ser considerados como grandes influenciadores de seu comportamento. Estima et. al. (2009) demonstraram a relevância dos aspectos sociais para criação de um padrão de consumo alimentar dos indivíduos. Foi evidenciado que a estrutura da família e o tipo de consumo de refeições familiares influenciam, diretamente, o consumo e a escolha alimentar das crianças e adolescentes.

Diante dessa lógica de delimitação de ação, a qual é direcionada por padrões comumente verificados a partir de influencia social, cabe afirmar que os agentes, geralmente, têm extrema dificuldade em expressar preferência por algo que é considerado "repugnante" frente a percepções morais aceitas socialmente. É de suma importância compreender que as escolhas feitas pelos agentes são, muitas vezes, realizadas de forma a ignorar as preferências pessoais próprias e sem consciência plena da tomada de decisões. Isso ocorre pelo fato de que as regras, as tradições, os "palpites", as normas, as culturas são os seus aspectos norteadores e, ainda, estão conectadas com uma espécie de consenso relacionado à ação dos outros (MARCH, 1991).

Nas organizações, de acordo com March (1991), o comportamento dos indivíduos é determinado por procedimentos operacionais padrão, normas profissionais, normas culturais e estruturas institucionais. Sendo assim, as decisões tomadas dentro e fora das organizações, envolvem a busca por regras "apropriadas" para seguir. Essa lógica da escolha se diferencia por considerar as identidades ao invés de apenas realçar as consequências no ato de escolher.

Um aspecto relevante para a sobrevivência de um indivíduo é a necessidade de construção de uma identidade. Esta identidade pode levar o indivíduo a agir conforme a construção de uma imagem de si mesmo e de facetas relacionadas ao seu modo de ser. Além disso, socialmente 
representa múltiplos papéis em diferentes momentos da sua experiência social. Desta forma, é capaz de igualar-se ou diferenciar-se mediante os vários grupos sociais de que faz parte, tornando-se uma unidade contraditória, múltipla e mutável (FERNANDES E ZANELLI, 2006).

Destarte, a identidade pode ser vista como a forma por meio da qual cada indivíduo, dotado de características heterogêneas, compõe um grupo, de etnia, raça, gênero, família ou profissão. A identidade pode ser constituída pela necessidade de sobrevivência, bem como pelas variabilidades intrínsecas das relações sociais e delimitadas no contexto de espaço e tempo em que o indivíduo está inserido (SANTINELLO, 2011). As identidades interferem no processo de tomada de decisão e nas escolhas dos indivíduos, que são dotados de sentimentos e afetos, baseada no atendimento das expectativas de comportamentos do "clã" do qual faz parte.

Em contraste com a teoria tradicional, a tomada de decisão é tratada por March (1994) por meio de uma lógica de adequação, qual seja, aquela em que o tomador de decisão considera como fonte para sua decisão um modelo ou padrão social constituído institucionalmente. Os gerentes, por exemplo, aprendem como devem monitorar, orientar, redigir relatórios, comportar-se em reuniões e agir conforme o escopo pertencente a uma identidade socialmente definida (MARCH, 1994).

A lógica do comportamento apropriado exposta em March (1994), é permeada pelo plano normativo das instituições. O indivíduo formula perguntas do tipo "Dado a situação, o que é esperado de mim?". A ação desencadeada é racional, na medida em que há direcionamento para um fim, porém o objetivo não é o retorno para o indivíduo. March (1994, p. 67 e 68) afirma "Identidades são contratos, motivos e cognições socialmente construídas que conectam-se com estruturas regulatórias organizacionais. E esta fina tapeçaria de obrigações controla muito do que é denominado tomada de decisão"6.

É inadequado falar de uma "racionalidade social" porque é difícil que um grupo de muitos indivíduos compartilhe exatamente de um mesmo querer. Indivíduos em interação de grupo identificamse com certos valores, aderem a normas livremente ou por constrangimento e convergem para objetivos grupalmente selecionados. As propensões a pensar e a agir seguem então uma lógica do comportamento apropriado dado o papel desempenhado pelo indivíduo para a consecução das diretrizes almejadas pelo grupo. Tais propensões são incorporadas à identidade individual e desencadeadas habitualmente, ou seja, sem necessariamente haver reiteradas deliberações.

A lógica de comportamento apropriado interfere na racionalidade limitada e processual; a identificação de um problema bem como a busca e a seleção de alternativas, bem como o nível de corte satisfatório dos indicadores de desempenho, estão condicionados pelas identidades assumidas pelas pessoas nas organizações. Por exemplo, as habilidades do sujeito, se engenheiro ou administrador de empresas, a sua posição na organização - controle, criação, terceirizado, etc. -, influenciam na identificação de problemas e no procedimento de solução.

Organizações também assumem identidades, por vezes cunhadas "posicionamento". À identidade de firma "com produtos e processos de alto padrão e caros" correspondem uma série de rotinas operacionais que diferem da outra que se projeta no mercado como "barateira e eficaz". Em ambientes de mercado, nos quais a sanção externa é tácita e nem sempre imediata (as vendas podem não cair, mas a empresa está deixando de entrar em novas franjas de mercado; empresas ineficientes com capital acumulado sobrevivem muito tempo), ou seja, prevalece o plano normativo sobre o regulativo, é fundamental que haja uma identidade direcionando as ações e reações das organizações.

Enquanto a lógica consequente implica consequências frente a preferências individuais cujas raízes sociais jamais são discutidas, a lógica do comportamento apropriado explicita que os indivíduos cumprem papéis sociais para desempenharem um papel aceito por um grupo social.

O indivíduo que emerge da lógica do comportamento apropriado é bem diferente do indivíduo simples da lógica da consequência, subjacente ao homo economicus. Na racionalidade consequente, se o indivíduo faz uma má escolha, isto é um problema seu. Na lógica das identidades, se ele não corresponder minimamente ao esperado será julgado, explícita ou tacitamente, sentirá vergonha ou culpa. Uma carga emocional está em jogo. Porém, segundo March (1994), o processo de construção de identidades não

\footnotetext{
${ }^{6}$ Tradução livre.
} 
reage apenas a sanções externas, ele implica a estruturação interna ao sujeito de interpretações que convirjam para o socialmente desejado, implicando um enraizamento e automatização dos papéis.

Um processo de escolha geralmente envolve uma ocasião em que os tomadores de decisão são imbuídos de virtudes e verdades próprias arraigadas que interferem na interpretação dos fatos e são capazes de gerar sentimentos, por exemplo, de culpa ou de glória, diante dos acontecimentos. Desta maneira, desafiam-se ou reafirmam-se amizades e relações de confiança nos relacionamentos, com vistas a gerar antagonismos, aprofundar relações de poder, status e oportunidade de socialização (MARCH, 1991).

Logo, os indivíduos e sua cognição são institucionalizados, pois são guiados por papéis e identidades, inclusive no que diz respeito ao seu aprendizado, já que, ao perceber várias possíveis opções, ele escolhe a partir de algo mais "apropriado". A lógica de apropriação reforça que o que "está em jogo" na tomada de decisão do indivíduo são os julgamentos que ele concebe que está praticando na ação. Com isso, as emoções dos indivíduos que o conduzem à escolha de preferência. Neste sentido, "as identidades dos indivíduos são construídas de acordo com o ambiente em que se inserem e envolvem, essencialmente, as estruturas sociais, a cultura e o histórico das relações" (FERNANDES E ZANELLI, 2006)

A noção de identidade nas instituições é resultante do relacionamento com outros, que é construído, mantido e modificado pelas características do contexto interativo. Ao compartilhar objetivos, regras, valores, os indivíduos assumem comportamentos grupais moldados pela instituição. Esses comportamentos são motivados pela redução da incerteza de como devem sentir, agir, pensar, e ainda, de como serão vistos pelos outros. O grupo sinaliza ações desejáveis e, consequentemente, a identidade social dos indivíduos. Assim, a identidade passa a ser entendida como o próprio processo de identificação (FERNANDES E ZANELLI, 2006) Desta forma, os indivíduos passam a se comportar de forma convergente ao que é esperado no grupo, com vistas a sentir-se pertencente e incluído.

Em suma, a tomada de decisão é uma arena para ação simbólica que possibilita interpretação de vida e dos fatos de forma diferentes, a partir da visão dos indivíduos, dotados de afetividade e identidades. As decisões são reflexos de crenças sobre as coisas e seus respectivos resultados. Esses processos de escolha podem ser globais e ordenados com a ideologia social ou locais e alinhados com as necessidades individuais de grupos específicos (MARCH, 1991).

\section{CONSIDERAÇÕES FINAIS}

O trabalho procurou demonstrar que existem diferentes abordagem que fazem alusão à cognição humana. A teoria neoclássica e suas variantes são insatisfatórias na medida em que não abordam os aspectos cognitivos heterogêneos presentes nos indivíduos e nas instituições, ou seja, nela não há visão de processo do aprendizado humano de produção e de consumo. O fundamento inócuo da racionalidade ilimitada para a tomada de decisões está no cerne desse pensamento. Como o objeto de estudo disseminado é a existência de recursos ilimitados, a problemática central dos agentes é a tomada de decisão frente ao uso desses recursos. Aqui, o tomador de decisões antecipa as consequências produtivas e distributivas, de modo que são antecipados também os resultados de suas ações. Essas consequências são avaliadas de acordo com o conjunto de preferências dos agentes. Tal visão é incipiente acerca da complexidade humana, mais especificamente da cognição.

Lancaster (1966) desafiou parcialmente esta tradição científica na economia ao relacionar as utilidades a serviços de consumo. A relação do sujeito não é com o bem, é com serviços de utilidade proporcionados por bens, o que leva a uma busca por alguns serviços que ele pode projetar em diferentes bens. Isto abriu a perspectiva de aprendizagem de consumo.

O pensamento evolucionário neoschumpeteriano, ao empreender esforços para compreender o processo de mudança tecnológica e institucional, distanciou-se da teorização mencionada na teoria tradicional. Reconhecem que incorporar elementos relativos à cognição do indivíduo é um ponto de partida para explicar situações de diferenciações existentes nas firmas e isso é fundamental para o avanço tecnológico. No entanto, ao integrar a existência da racionalidade limitada, apesar de avançar na esfera da cognição, o fazem ainda sem incorporar consistentemente os elementos de identidade social, ou seja, não há rompimento paradigmático radical e sim incremental vis-à-vis a abordagem tradicional. Avançaram ao 
renegar os cânones tradicionais, da seguinte forma: i) aceitando que a realidade econômica se dá fora de uma noção de equilíbrio geral; ii) concebendo uma ideia não reducionista do indivíduo; ii) enfatizando o aprendizado compartilhado.

Veblen ao romper com o paradigma neoclássico concebe uma nova sistemática acerca do indivíduo. De início, contrapõe a vertente behavorista que afirma que os indivíduos agem de forma automática e passível a estímulos. Salienta que, não há comportamento social se não houver mediação e interpretação de significados pelos indivíduos, o que traz à tona a importância da cognição. Insere elementos essenciais na sua teoria, como instintos, e as instituições, que são capazes de alcançar uma explicação do indivíduo adaptável ao meio mais consistente. Exemplifica seu pensamento com base no consumidor conspícuo, que atua como observador com base na aprendizagem vicária.

Scott proporciona importante contribuição para a abordagem institucionalista ao definir os pilares das instituiçõoes, em particular, por explicitar uma esfera específica para a cognição. Esclarece que as instituições são compostas por elementos regulativos, normativos, cultural e cognitivos, com atividades inter-relacionadas, que são capazes de promover estabilidade e significado de vida social. Especificamente no pilar cognitivo, emerge a ideia de cultura como agregação de significações de atos e gestos, ou seja, a cognição e interpretação da realidade acontecem de forma compartilhada. Um exemplo disso é que a percepção institucionalizada da resolução de problemas, em dada comunidade, que está condicionada a aprendizados de ciclos anteriores. Nesse sentido, as instituições do passado são capazes de modelar a assimilação da compreensão do presente.

Já March vai além da lógica do cômputo, mesmo que imperfeito, da consequência da ação. Para o autor, as ações dos indivíduos se adéquam a vários fins que não implicam, necessariamente, deliberações conscientes. O comportamento "adequado" e "eficiente" estaria relacionado à decisão comportamental apropriada socialmente. Neste sentido, o indivíduo, na maioria das vezes se pergunta: "como devo agir dado o que a instituição espera de mim?" Desta forma, a deliberação está condicionada a uma expectativa social, logo um "protocolo". Dada a institucionalização da cognição dos indivíduos, suas escolhas são guiadas ao considerar o mais apropriado, diante do "julgamento" social, mediante interferências de suas emoções, como, por exemplo, o desejo de se sentir aceito socialmente, como aspecto norteador de suas ações. A lógica de comportamento apropriado pode enriquecer a compreensão da racionalidade limitada e processual, na medida em que liga a cognição a papéis coais, ou seja, a identificação de um problema bem como a busca e a seleção de alternativas, bem como o nível de corte satisfatório dos indicadores de desempenho, estão condicionados pelas identidades assumidas pelas pessoas nas organizações.

Por fim, todas as abordagens, mesmo que em diferentes ângulos, diferem da lógica tradicional de indivíduo e promovem rupturas ou contribuições importantes relacionadas à cognição, ao aprendizado e ao comportamento social do indivíduo. São complementares umas às outras na construção teórica para a compreensão dos processos de decisão individual e sua repercussão nas mudanças econômicas e sociais.

\section{REFERÊNCIAS BIBLIOGRÁFICAS}

ALMEIDA, Jose Felipe Araujo de. Thorstein Veblen and Albert Bandura: a modern psychological reading of the conspicuous consumer. Journal of Economic Issues, v. 48, n. 1, p. 109-122, 2014.

ALMEIDA, Jose Felipe Araujo de. Uma abordagem institucional-psicológica da tomada de decisão dos consumidores. 2011.

BANDURA, Albert. Social foundations of thought and action: a social cognitive theory. New Jersey: Prentice Hall, 1986.

CAVALCANTE, Carolina Miranda. Institutional economics and the three dimensions of institutions. Revista de Economia Contemporânea, v. 18, n. 3, p. 373-392, 2014. 
CONCEIÇÃO, Octavio Augusto Camargo. O conceito de instituição nas modernas abordagens institucionalistas. Revista de economia contemporânea. Rio de Janeiro. Vol. 6, n. 2 (jul./dez. 2002), p. 119-146, 2002.

DA COSTA, Fernando Nogueira. Comportamentos dos investidores: do homo economicus ao homo pragmaticus. 2009.

DA GAMA CERQUEIRA, Hugo EA. Sobre a filosofia moral de Adam Smith. Síntese: Revista de Filosofia, v. 35, n. 111, p. 57-86, 2010.

DA SILVA, Vagner Luís. Fundamentos do institucionalismo na teoria social de Thorstein Veblen. Política \& Sociedade, v. 9, n. 17, p. 289-323, 2010.

DEMO, Pedro. Introdução da Metodologia. São Paulo: Atlas, 1985.

ENDERLE, Rogério; GUERRERO, Glaison. A herança patrimonialista na burocracia estatal do Brasil: path dependence patrimonialista $\mathrm{e}$ a falta da autonomia enraizada do estado brasileiro. ENCONTRO DE ECONOMIA DA REGIÃO SUL, v. 11, 2008.

ESTIMA, Camilla de Chermont Prochnik et al. Fatores determinantes de consumo alimentar: por que os indivíduos comem o que comem?. Revista brasileira de nutrição clínica, v. 24, n. 4, p. 263-268, 2009.

FERNANDES, Karina Ribeiro; ZANELLI, José Carlos. O processo de construção e reconstrução das identidades dos indivíduos nas organizações. Revista de Administração Contemporânea, v. 10, n. 1, p. 55-72, 2006.

GARCIA, Bruno Gaspar. Responsabilidade social das empresas: a contribuição das universidades. Editora Peirópolis, 2002.

HODGSON, Geoffrey M. Thorstein Veblen and post-Darwinian economics.Cambridge Journal of Economics, Cambridge, n. 16(3), p. 285-301. 1992.

JUNIOR, Ronaldo Rodrigues Teixeira; SOUZA, MAO de. Vocabulário de Análise do Comportamento: um manual de consulta para termos usados na área. Santo André: esetec, 2006.

LANCASTER, Kelvin J. A new approach to consumer theory. Journal of political economy, v. 74, n. 2, p. 132-157, 1966.

LONG, Norman; PLOEG, Jan Douwe van der. Demythologizing planned intervention: an actor perspective. Sociologia Ruralis, v. 29, n. 3-4, p. 226-249, 1989.

LOUVIERE, J. J.; HENSHER, D. A.; SWAIT, J. D. Stated Choice Methods: Analysis and Application. Cambridge: Cambridge University Press, 2000.

MARCH, James G. How decisions happen in organizations. Human-computer interaction, v. 6, n. 2, p. 95-117, 1991.

MARCH, James G. Primer on decision making: How decisions happen. Simon and Schuster, 1994.MARCH 1994.

Markus, H., \&Zajonk, R.B. 1985. The cognitive perspective in social psychology.In G.Lindsey\& E. Aronson (Eds.) Handbook of social psychology: 137-230. New York: Random House. 
MATURANA, Humberto R. et al. Cognição, ciência e vida cotidiana. Belo Horizonte: Ed. UFMG, 2001.

MONASTERIO, Leonardo Monteiro. Veblen e o Comportamento Humano: uma avaliação após um século de "A Teoria da Classe Ociosa". Cadernos IHU Idéias, v. 42, n. 3, 2005.

NELSON RICHARD, R.; WINTER SIDNEY, G.An evolutionary theory of economic change. Harvard Business School Press, Cambridge, 1982.

NELSON, Richard R.; WINTER, Sidney G. Evolutionary theorizing in economics. The journal of economic perspectives, v. 16, n. 2, p. 23-46, 2002.

NELSON, Richard R.; WINTER, Sidney G. Uma teoria evolucionária da mudança econômica. Editora Unicamp, 2005.

PINKER, S. O instinto da linguagem: Como a mente cria a linguagem (1954). Tradução Claudia Berliner. São Paulo: Martins Fontes, 2002.

SANTINELLO, Jamile. A identidade do indivíduo e sua construção nas relações sociais: pressupostos teóricos. Revista de Estudos da Comunicação, v. 12, n. 28, 2017.

SCOTT, W. Richard et al. Institutional theory: Contributing to a theoretical research program. Great minds in management: The process of theory development, v. 37, p. 460-484, 2005.

SCOTT, W. Richard. Approaching adulthood: the maturing of institutional theory. Theory and society, v. 37, n. 5, p. 427, 2008.

SCOTT, W. Richard. Instituitions and organizations. Thousande Oakes: Sage, 2001.

SIMON, Herbert A. Rationality as process and as product of thought. The American economic review, p. 1-16, 1978.

STEINGRABER, Ronivaldo; FERNANDEZ, Ramon Garcia. A racionalidade limitada de Herbert Simon na Microeconomia. Revista da Sociedade Brasileira de Economia Política, n. 34, 2013.

Wicks, D. 2001.Institutionalized mindsets of invulnerability: Differentiated institutional fields and the antecedents of organizational crisis. Organization Studies, 22(4): 659-692.

ZULIAN, A. Indivíduos e comportamento: aspectos cognitivos, institucionais e identidades sociais. 2015. Dissertação (Mestrado em Economia e Desenvolvimento) - Universidade Federal de Santa Maria, Santa Maria, 2015. 